\title{
Evaluation of Lipid Profiles of Children and Youth from Basic Health Units in Campinas, SP, Brazil: A Cross-Sectional Laboratory Study
}

\author{
Érica Ivana Lázaro Gomes, ${ }^{10}$ Vanessa Helena de Souza Zago, ${ }^{2}$ Eliana Cotta de Faria ${ }^{1}$ \\ Universidade Estadual de Campinas - Patologia Clínica, ${ }^{1}$ Campinas, SP - Brazil \\ Pontifícia Universidade Católica de Campinas (PUC - Campinas), ${ }^{2}$ Campinas, SP - Brazil
}

\begin{abstract}
Background: Among dyslipidemias, hypercholesterolemia is considered the main risk factor for cardiovascular diseases in adults. In childhood and adolescence, elevated total cholesterol (TC) and low-density lipoprotein cholesterol (LDL-C) are positively associated with atherosclerosis markers, however, systematic screening for dyslipidemias in these groups is a controversial topic.

Objective: To characterize the frequencies, types and severity of dyslipidemias in children and adolescents attended at the Basic Health Units managed by SUS in Campinas/SP.

Methods: After an agreement with the Municipal Health Department of Campinas, consecutive results of serum lipid profiles $(n=312,650)$ of individuals of both sexes $(n=62,530)$ aged between 1 day old and 19 years were obtained, from 2008 to 2015. Age groups and dyslipidemias were classified according to recommendations in the literature. The statistical significance level adopted was the probability value (p) of 0.05 or less.

Results: The observed frequencies of increased TC, triglycerides (TG), LDL-C and non-HDL-C (NHDL-C) were 33\%, $40 \%, 29 \%$ and $13 \%$ respectively, and of reduced high-density lipoprotein cholesterol (HDL-C) the frequency was $39 \%$. The frequencies, in general, were greater in females and in the southwest and south regions of the city, whose populations are more vulnerable from the socioeconomic point of view; on the other hand, in children and adolescents, the frequencies of TG and HDL-C prevailed, respectively.
\end{abstract}

Conclusions: The high frequency and regionalization of dyslipidemias in children and adolescents indicate the need for specific actions in the handling and treatment of such diseases by the public health system of Campinas. (Arq Bras Cardiol. 2020; 114(1):47-56)

Keywords: Cardiovascular Diseases; Dyslipidemias; Hypercholesterolemia; Child; Young Adult; Unified Health System; Adolescent; Laboratory Test.

\section{Introduction}

Cardiovascular diseases (CVD) represent one of the main causes of morbidity and mortality in Brazil and worldwide. According to the World Health Organization (WHO), in 2015 CVD accounted for $31 \%$ of deaths worldwide. ${ }^{1}$ In Brazil, $29 \%$ of deaths were due to CVD according to the Brazilian Society of Cardiology. ${ }^{2}$

Dyslipidemias play a well-established role in cardiovascular risk in adults, and so do hypertension, diabetes mellitus, early family history of coronary artery disease and smoking. Often these clinical situations are associated with comorbidities such as overweight, obesity, poor eating habits

MailingAddress: Eliana Cotta de Faria •

Universidade Estadual de Campinas - Patologia Clínica - Rua Tessália Vieira de Camargo, 126. Postal Code 13083-887, Cidade Universitária Zeferino Vaz Campinas, SP - Brazil

E-mail: cottadefaria@gmail.com

Manuscript received June 29, 2018, revised manuscript February 12, 2019, accepted March 10, 2019

DOI: $10.5935 / a b c .20190209$ and physical inactivity, ${ }^{1,3}$ with serious consequences for the individual and the public health system. ${ }^{4}$

Children and adolescents account for $34 \%$ of the Brazilian population, an absolute contingent of 57,1 million people. ${ }^{5}$ There is evidence that high levels of total cholesterol (TC) and low-density lipoprotein cholesterol (LDL-C) in childhood and adolescence are associated with atherosclerotic outcomes in young adults. In this context, Napoli et al. ${ }^{6}$ demonstrated fatty streaks in the intrauterine life span, being more noticeable in pregnant women with hypercholesterolemia.

Unlike the Brazilian Dyslipidemia Directive (DBD) Update, universal lipid screening over two years of age as compared to that of children with risk factors ${ }^{3}$ was recommended, based on other studies, by Zachariah and Johnson ${ }^{7}$ for having a greater diagnostic sensitivity by $30 \%$ to $60 \%$. In Brazil, there are few population studies involving dyslipidemias in childhood and adolescence. ${ }^{8}$ In addition, the Study of Cardiovascular Risks in Adolescents (ERICA) stands out, with a national approach and covering a population of 80,000 young people between 12 and 17 years old. ${ }^{8}$

A previous study in our laboratory characterized severe dyslipidemias in the juvenile population in a public hospital 
segment in Campinas. ${ }^{9}$ However, there are still gaps regarding their characterization in regional terms. Thus, this study was designed to characterize the frequencies, types and severity of dyslipidemias in children and adolescents attended at the Basic Health Units (UBS) in Campinas, SP.

\section{Methods}

This is a retrospective cross-sectional study based on monthly lipid profile databases, which were periodically sent to the Lipid Laboratory of the School of Medical Sciences of UNICAMP through an academic agreement with the Municipal Health Department of Campinas.

Between 2008 and 2015 312,650 results of serum laboratory tests were obtained from 62,530 individuals of both sexes, aged between one day and 19 years who visited UBS in the city of Campinas, SP, for medical outpatient care. The UBS are distributed over five regions or health districts of the city.

Only individuals with measured serum lipid profile were included in the study, with the following parameters: TC, triglycerides (TG), LDL-C, high-density lipoprotein cholesterol (HDL-C) and non-HDL-C (NHDL-C). These analyses were performed by enzymatic-colorimetric and/or direct homogenous methods for LDL, according to the quality control standards of the Brazilian Society of Clinical Pathology, including the blood collection stage in the UBS. NHDL-C was calculated. ${ }^{10}$ A single chemical analyzer, Modular ${ }^{\circledR}$ Analytics Evo (Roche Diagnostics, Burgess Hill, West Sussex, UK), and reagents from Roche Diagnostics $₫$ (Mannheim, Germany) were used during the study period.

Dyslipidemias were classified biochemically in consonance with the cut-off values for age advocated by the current $\mathrm{DBD}^{3}$ as: isolated increases of LDL-C, TG, NHDL or reductions of HDL-C; mixed dyslipidemias, defined as lipid combinations of increased LDL-C and TG and/or increased LDL-C and reduced HDL-C and/or increased TG and reduced HDL-C.

We used the reference values of Kwiterovich $\mathrm{PO}^{11}$ for infants (children from one day to 23 months of age), once there are no DBD recommendations for this age group, except for TG in the 0-9 years of age group. For NHDL-C in all age groups, also absent in DBD recommendations, the desirable and undesirable values ( $<123$ and $\geq 144$ ) of Kwiterovich PO were used as well.

In order to determine the groups of children (2-11 years of age) and adolescents (12 to 19 years of age) we followed the Brazilian Child and Adolescent Statute definitions (Law $\mathrm{n}^{\circ}$. 8.069/90 updated with Law no. 12.010 of 2009), with adaptation of the upper limit for adolescents because of DBD, and the recommendations therein, between two and 19 years of age. ${ }^{3}$ The cut-off values $(\mathrm{mg} / \mathrm{dL})$ used as desirable and undesirable are shown in Table 1.

Lipid profiles were also evaluated for LDL-C $\geq$ $190 \mathrm{mg} / \mathrm{dL}$, without concomitant hypertriglyceridemia, for laboratory characterization of possible cases of Familial Hypercholesterolemia (FH). ${ }^{10}$

The city of Campinas is a Sao Paulo inland city that has approximately 1.1 million residents, ${ }^{12}$ with 63 UBS distributed over five health districts: East (E), Northwest (NW), North (N), Southwest (SW) and South (S). ${ }^{13}$

\section{Statistical analysis}

The variables, either continuous or categorical, were analyzed using descriptive and comparative tests in software SPSS 24.0 (SPSS Inc., USA) and SAS 9.4 (Inc, Cary, NC, USA). Since there was only one lipid profile available for some individuals and for others several were available during the study, only a single and first lipid profile per year were used in the study period (2008-2015).

Tests were performed to verify the normality of data distribution (Kolmogorov-Smirnov). The groups were then compared by the Mann-Whitney and Kruskal-Wallis tests with Bonferroni post-test, with data presented as median and interquartile ranges for the continuous variables, and chi-square $\left(\mathrm{X}^{2}\right)$ test with the post-test for multiple comparisons in contingency tables based on permutations for categorical variables. Values of $p<0.05$ were considered significant.

\section{Results}

Figure 1 shows the distribution of the five health districts of Campinas with the respective numbers observed for

Table 1 - Reference values for lipids and lipoproteins in children and adolescents

\begin{tabular}{|c|c|c|c|}
\hline \multirow{2}{*}{ Lipidic variables } & \multicolumn{3}{|c|}{ Values (mg/dL) } \\
\hline & Desirable & Undesirable (1 day to 23 months) & Undesirable (2 to 19 years) \\
\hline $\mathrm{TC}$ & $<170$ & $\geq 200$ & $\geq 170$ \\
\hline LDL-C & $<110$ & $\geq 130$ & $\geq 110$ \\
\hline NHDL-C & $<123$ & $\geq 144^{*}$ & - \\
\hline \multicolumn{4}{|l|}{ TG } \\
\hline $0-9$ years & $<75$ & $\geq 100$ & $\geq 75^{\star *}$ \\
\hline $10-19$ years & $<90$ & $\geq 130$ & $\geq 90$ \\
\hline HDL-C & $>45$ & $<35$ & $\leq 45$ \\
\hline
\end{tabular}

Reference values for 1 day to 23 months old: *NHDL-C $\geq 1441$ day to 19 years old. ${ }^{* *} T G \geq 75$ according to current DBD. TC: total cholesterol; LDL-C: low-density lipoprotein cholesterol; HDL-C: high-density lipoprotein cholesterol; NHDL-C: non high-density lipoprotein cholesterol; TG: triglycerides. 


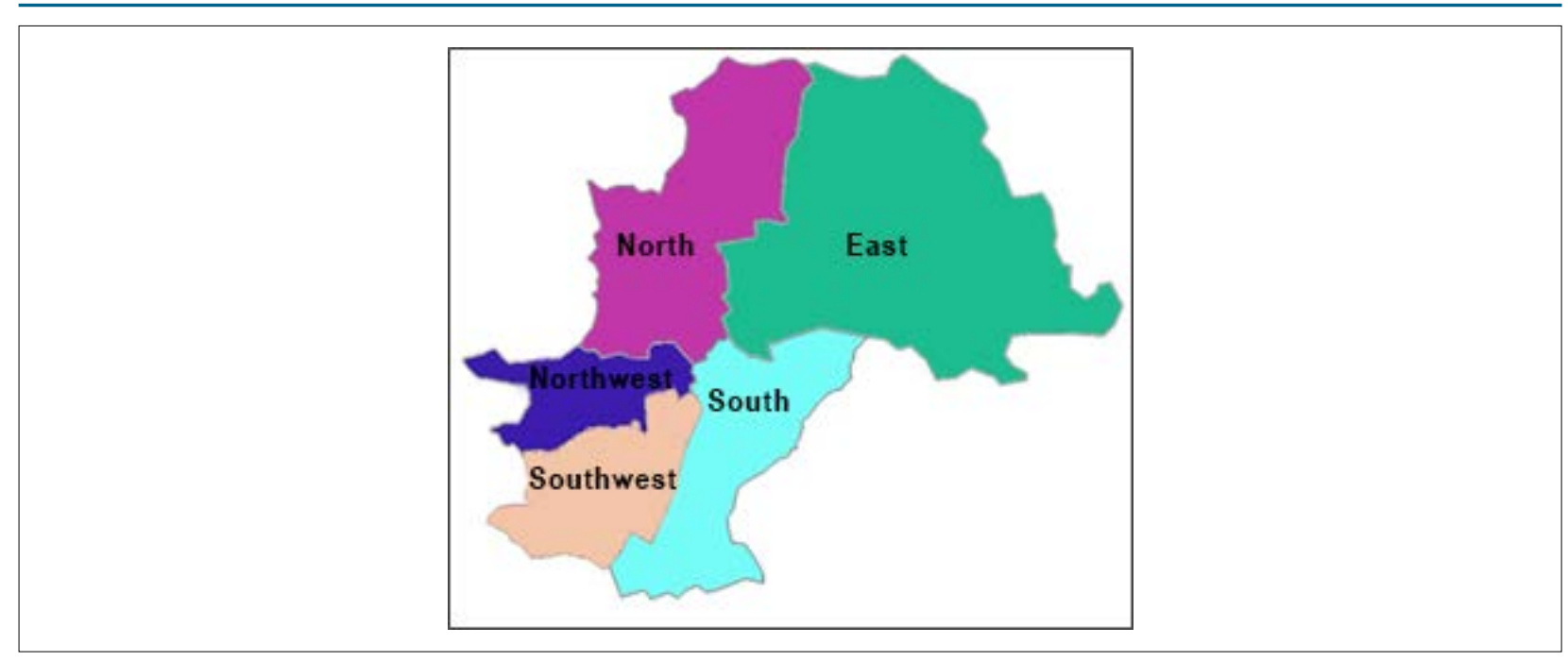

Figure 1 - Corresponding area to the health districts in the map of the city of Campinas. Source: Campinas Health Department. ${ }^{13}$

test results, of individuals evaluated and their percentage frequencies: East: 41,075 and 8,215 (13\%); Northwest: 61,900 and 12,380 (20\%); North: 52,975 and 10,595 (17\%); Southwest: 79,305 and 15,861 (25\%) and South: 77,395 and $15,479(25 \%)$. Half of the tests came from the southwest and south regions.

Table 2 summarizes the demographic characteristics of subjects, including the origin of clinical laboratory calls.

The results of the descriptive and comparative analyses are shown in Tables 3 and 4.

Table 3 shows that in all the age groups, TC, TG, LDL-C and NHDL-C were higher for infants. TG was similar in children and adolescents, and the median of HDL-C levels was higher in children than in the others. In relation to sex, the female group had higher values.

In the comparison by age group, the results also showed significant differences for the parameters evaluated in both sexes.

Table 4 clearly shows that there were higher results for TC in the eastern region than in the other regions. LDL-C levels were higher in the eastern region than in the northwest, southwest and south; NHDL-C values were also higher in this region than in the south and lower in the northwest region than in the others.

In the eastern, north, and southwestern regions, triglyceridemia was higher than in the northwestern region, and in the eastern and southwestern regions, it was higher than in the south. HDL-C in the southwestern region was lower than in the other ones and higher in the eastern region than in the south.

Table 5 shows the frequencies of dyslipidemia and their ratios by sex.

The most frequent dyslipidemias were isolated increases in TG and reduction of HDL-C. By sex, dyslipidemia frequencies were higher in females.

Figure 2 shows the frequencies of dyslipidemia by age. Infants presented higher frequencies of increased TG and
Table 2 - Demographic characteristics of all subjects and by sex and age

\begin{tabular}{lcc}
\hline Features & Number of individuals & Total frequencies total (\%) \\
\hline Total & 62,530 & 100 \\
Sex & & \\
F & 34,932 & 56 \\
M & 27,598 & 44 \\
Age & & \\
Infants & 660 & 1 \\
F & 399 & 0.6 \\
M & 261 & 0.4 \\
Children & 25,501 & 41 \\
F & 13,219 & 21 \\
M & 12,282 & 20 \\
Adolescents & 36,369 & 58 \\
F & 21,314 & 34 \\
M & 15,055 & 24 \\
\hline
\end{tabular}

N: number; F: female; M: male.

NHDL-C and isolated dyslipidemias, as well as a higher prevalence of the combination of increased LDL-C and TG.

As for children, higher levels of TC and LDL-C were observed, as well as the combination of increased TG and reduced HDL-C; there was also a higher frequency of at least one type of mixed dyslipidemia. On the other hand, adolescents showed a higher number of reduced HDL-C results.

Figure 3 shows the frequencies of dyslipidemia by regions of Campinas.

Dyslipidemias were more frequent in the southwestern region of Campinas than in the other regions. 
Table 3 - Lipid profiles: medians and interquartile ranges for all subjects and stratified by sex and age

\begin{tabular}{|c|c|c|c|c|c|c|}
\hline Groups & Lipids (mg/dL) & Total & Female & Male & $\mathrm{p}^{*}$ & $\mathbf{p}^{\dagger}$ \\
\hline \multirow{5}{*}{ All } & TC & $156(137-178)$ & $158(139-179)^{\dagger}$ & $154(135-176)$ & & 0.000 \\
\hline & TG & $76(57-103)$ & $78(59-105)^{\dagger}$ & $73(54-100)$ & & 0.000 \\
\hline & LDL-C & 95 (78-114) & $96(79-114)^{\dagger}$ & 93 (77-112) & & 0.000 \\
\hline & HDL-C & $49(41-57)$ & $49(42-57)^{\dagger}$ & $48(41-57)$ & & 0.000 \\
\hline & NHDL-C & $106(88-127)$ & $107(89-128)^{\dagger}$ & $104(86-125)$ & & 0.000 \\
\hline \multirow{5}{*}{ Infants (I) } & TC & $172(151-202)^{*}$ & $177(153-206)^{\dagger}$ & $167(147-193)$ & 0.000 & 0.019 \\
\hline & TG & $91(67-131)$ * & $94(68-132)$ & 87 (64-119) & 0.000 & 0.068 \\
\hline & LDL-C & $108(88-132)^{*}$ & $110(88-134)$ & $105(88-128)$ & 0.000 & 0.138 \\
\hline & HDL-C & $46(39-56)$ & $47(39-58)$ & $45(38-53)$ & & 0.063 \\
\hline & NHDL-C & $125(101-150)^{*}$ & 128 (101-153) & $119(102-147)$ & 0.000 & 0.108 \\
\hline \multirow{5}{*}{ Children $(\mathrm{C})$} & TC & $162(143-182)$ & $162(143-182)$ & 161 (143-182) & & 0.901 \\
\hline & TG & $75(56-103)$ & $79(60-109)^{\dagger}$ & $71(53-97)$ & & 0.000 \\
\hline & LDL-C & $99(83-118)$ & $100(84-118)^{\dagger}$ & $99(83-117)$ & & 0.013 \\
\hline & HDL-C & $50(42-58)^{*}$ & $49(41-57)$ & $51(43-60)^{\dagger}$ & 0.000 & 0.000 \\
\hline & NHDL-C & $110(93-130)$ & $111(94-131)^{\dagger}$ & $109(92-129)$ & & 0.000 \\
\hline \multirow{5}{*}{ Adolescents (A) } & TC & $153(133-174)$ & $155(136-177)^{\dagger}$ & 147 (128-168) & & 0.000 \\
\hline & TG & $76(57-102)$ & $76(58-103)^{\dagger}$ & $74(56-102)$ & & 0.000 \\
\hline & LDL-C & $91(75-110)$ & $93(77-111)^{\dagger}$ & $88(72-107)$ & & 0.000 \\
\hline & HDL-C & $48(41-56)$ & $49(42-58)^{\dagger}$ & $46(39-54)$ & & 0.000 \\
\hline & NHDL-C & $102(84-123)$ & $105(86-125)^{\dagger}$ & $99(82-120)$ & & 0.000 \\
\hline
\end{tabular}

F: female; M: male; (†) Mann-Whitney, F vs. M; $p<0.05$. (*) Kruskal Wallis Post-hoc Bonferroni, I vs C vs A = TC, LDL-C, NHDL-C - $>>C>A ; T G$ - I>C $=A ; H D L-C$ $C>A>1, p<0.05$; Continuous variables appear as medians and interquartile ranges. TC: total cholesterol; TG: triglycerides; LDL-C: low-density lipoprotein cholesterol; HDL-C: high-density lipoprotein cholesterol; NHDL-C: non high-density lipoprotein cholesterol.

Table 4 - Lipid profiles: medians and interquartile ranges for all subjects and by regions of campinas

\begin{tabular}{lcccccc}
\hline Lipids (mg/dL) & East (E) & Northwest (NO) & North (N) & Southwest (SO) & South (S) & $\mathbf{p}$ \\
\hline TC & $158(139-179)^{*}$ & $155(136-177)$ & $157(138-178)$ & $156(136-177)$ & $156(137-177)$ & 0,000 \\
TG & $77(58-105)^{*}$ & $74(56-101)$ & $76(57-103)$ & $77(58-105)^{*}$ & $75(56-103)$ & 0,000 \\
LDL-C & $96(79-115)^{*}$ & $94(77-113)$ & $95(79-114)$ & $94(78-113)$ & $95(78-113)$ & 0,000 \\
HDL-C & $49(42-58)$ & $49(41-57)$ & $49(42-57)$ & $48(41-56)^{*}$ & $49(41-57)$ & 0,000 \\
NHDL-C & $107(89-128)^{*}$ & $104(86-125)$ & $106(88-127)$ & $106(88-127)$ & $105(88-126)$ & 0,000 \\
\hline
\end{tabular}

$\left(^{*}\right)$ Kruskal-Wallis Post-hoc Bonferroni, TC: $E>$ others; $N>N W / S W ; T G$ : E/N/SW>NW; E/SW>S; LDL-C: E>NW/SW/S; N>NW; HDL-C: E>S; SW < others; NHDL-C: E>S; NW<others; $p<0.05$. Continuous variables appear as medians and interquartile ranges. TC: total cholesterol; TG: triglycerides; LDL-C: low-density lipoprotein cholesterol; HDL-C: high-density lipoprotein cholesterol; NHDL-C: non high-density lipoprotein cholesterol.

\section{Discussion}

The development of atherosclerotic plaques is directly associated with an increase in NHDL-C lipoproteins, and evidence suggests that childhood cardiovascular risk factors such as dyslipidemia may contribute to atherosclerotic disease in childhood and adolescence, as well as in adulthood. ${ }^{14}$

In this sense, the ongoing International Childhood Cardiovascular Cohort (i3C) Consortium ${ }^{15}$ aims to evaluate the association of the presence of risk factors in childhood with the outcomes of CVD morbidity and mortality in adults.
Preliminary results showed that pediatric dyslipidemia predicts dyslipidemia ${ }^{16}$ and greater carotid intima-media thickness ${ }^{17}$ in adults. In addition, the presence of risk factors developed from the age of nine was predictive of subclinical atherosclerosis in adults. ${ }^{18}$

In the present study, $67 \%$ of lipid profile results indicated the presence of at least one type of biochemically classified dyslipidemia. This percentage is greater than the one reported in other national studies: one of them, for example, carried out in the northeastern region of Brazil between 2011 and 2012, 


\section{Original Article}

Table 5 - Frequencies of isolated and mixed dyslipidemias in all subjects and by sex

\begin{tabular}{|c|c|c|c|c|c|c|c|c|}
\hline Dyslipidemias & $\mathrm{N}$ & All (\%) & $\mathrm{N}$ & $F(\%)$ & $\mathbf{N}$ & $M(\%)$ & Frequency ratios (\%) (F/M) & $p$ \\
\hline Isolated dyslipidemias & 41,689 & 67 & 23,572 & $38^{*}$ & 18,117 & 29 & 1.3 & 0.000 \\
\hline $\mathrm{TC} \uparrow$ & 20,759 & 33 & 12,213 & $19^{*}$ & 8,546 & 14 & 1.4 & 0.000 \\
\hline $\mathrm{TG} \uparrow$ & 24,703 & 40 & 14,527 & $23^{*}$ & 10,176 & 16 & 1.4 & 0.000 \\
\hline LDL-C $\uparrow$ & 18,299 & 29 & 10,594 & $17^{*}$ & 7,705 & 12 & 1.4 & 0.000 \\
\hline $\mathrm{HDL}-\mathrm{C} \downarrow$ & 24,210 & 39 & 13,120 & $21^{*}$ & 11,090 & 18 & 1.2 & 0.000 \\
\hline NHDL-C $\uparrow$ & 7,847 & 13 & 4,665 & $8^{*}$ & 3,182 & 5 & 1.5 & 0.000 \\
\hline Mixed dyslipidemias & 20,205 & 32 & 11,682 & $19^{*}$ & 8,523 & 14 & 1.4 & 0.000 \\
\hline LDL-C $\uparrow$ and $\mathrm{TG} \uparrow$ & 10,903 & 17 & 6,485 & $10^{*}$ & 4,418 & 7 & 1.5 & 0.000 \\
\hline $\mathrm{HDL}-\mathrm{C} \downarrow$ and $\mathrm{TG} \uparrow$ & 12,978 & 21 & 7,270 & 12 & 5,708 & 9 & 1.3 & 0.692 \\
\hline $\mathrm{HDL}-\mathrm{C} \downarrow$ and LDL-C $\uparrow$ & 6,960 & 11 & 3,901 & 6 & 3,059 & 5 & 1.3 & 0.742 \\
\hline
\end{tabular}

F: female; M: male; Chi-square test (X2); F vs M; $p<0.05$. TC: total cholesterol; TG: triglycerides; LDL-C: low-density lipoprotein cholesterol; HDL-C: high-density lipoprotein cholesterol; NHDL-C: non high-density lipoprotein cholesterol.

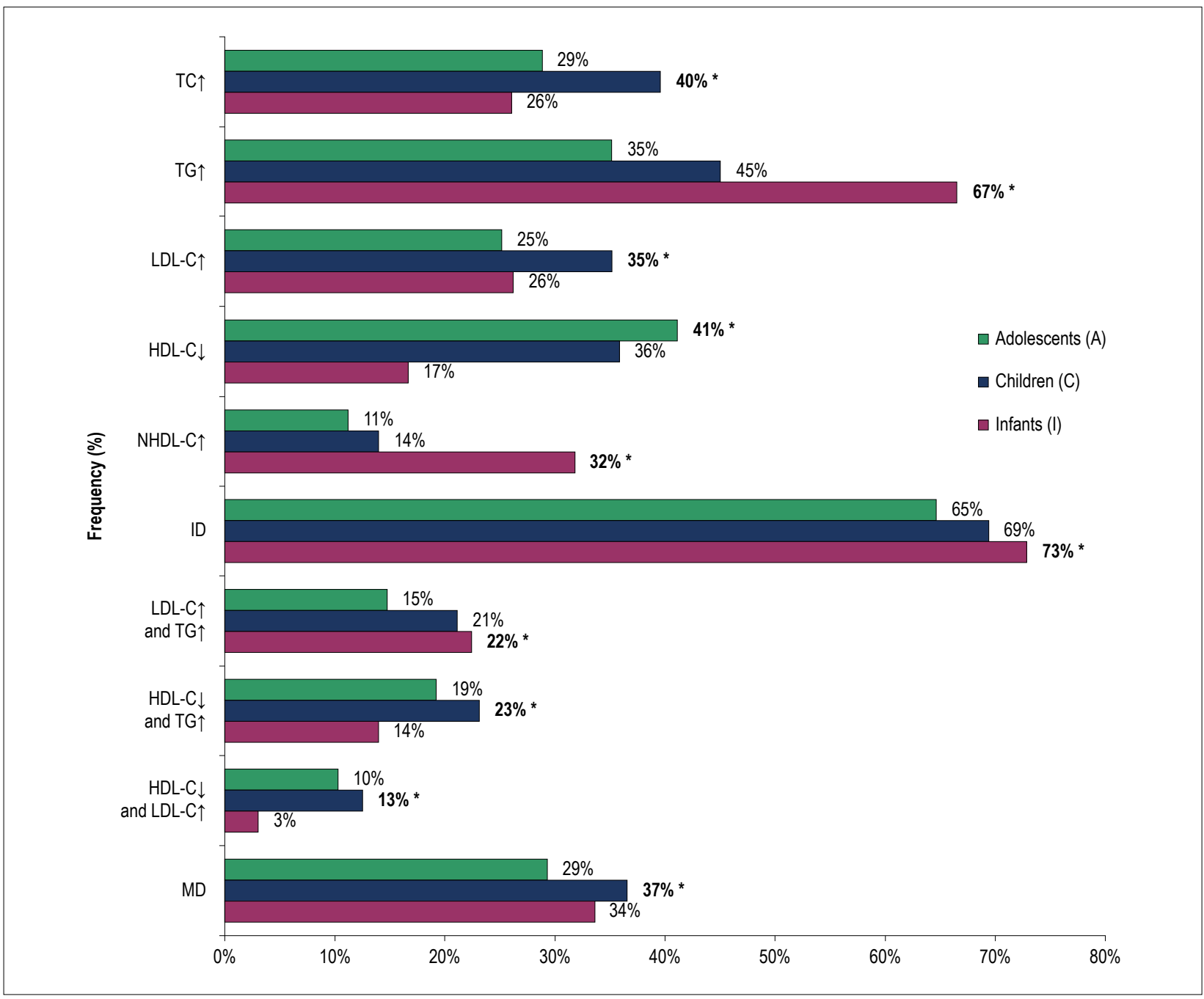

Figure 2 - Frequencies of isolated and mixed dyslipidemias by age; ID: Isolated dyslipidemias; MD: Mixed dyslipidemias; ${ }^{*}$ Chi-Square test $\left(X^{2}\right) ;$ I vs $C$ vs. $A ; p<0.05$;

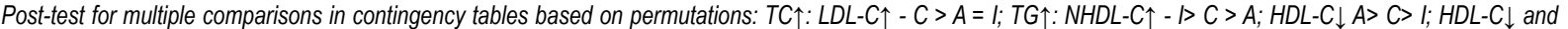
$T G \uparrow$ and HDL-C $\downarrow$ and $L D L-C \uparrow-C>A>I ; I D, L D L-C \uparrow$ and $T G \uparrow: M D-A<C=I ; p<0.05$. TC: total cholesterol; TG: triglycerides; LDL-C: low-density lipoprotein cholesterol; HDL-C: high-density lipoprotein cholesterol; NHDL-C: non high-density lipoprotein cholesterol. 


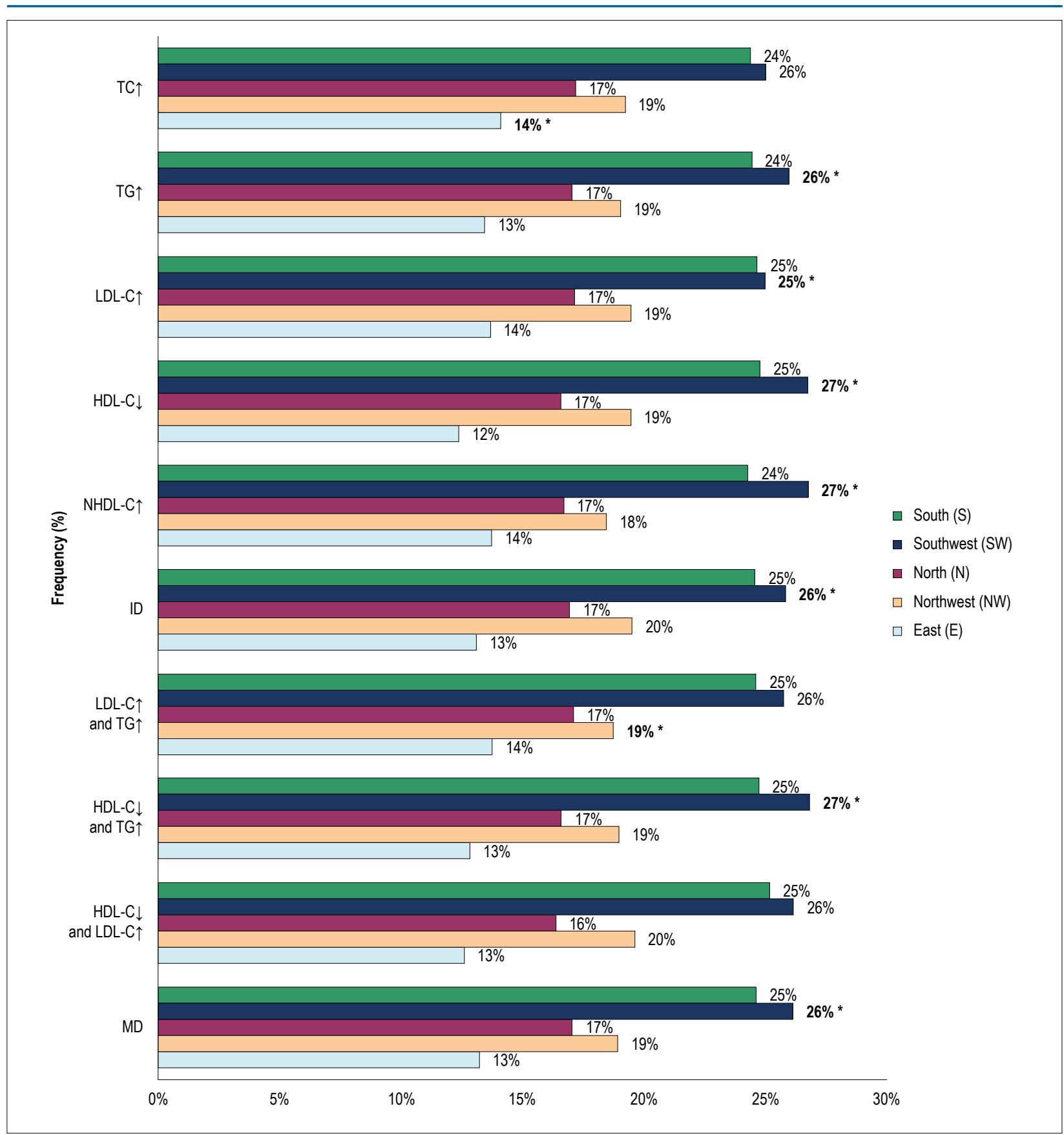

Figure 3 - Frequencies of isolated and mixed dyslipidemias by regions of campinas; ID: Isolated dyslipidemias; MD: Mixed dyslipidemias; *Chi-Square test (X2); Evs NW vs $N$ vs $S W$ vs $S ; p<0.05$; Post-test for multiple comparisons in contingency tables based on permutations: $T C \uparrow=E<$ others; $T G \uparrow, N H D L-C \uparrow=S W>N W>E ; L D L-C \uparrow=S W>$ $E<N W ; H D L-C \downarrow=S W>$ others, $S>E ; I D=N W<S W>S ; L D L-C \uparrow$ and $T G \uparrow=-N W>L ; H D L-C \downarrow$ and $T G \uparrow=S W>N W>N>E ; M D=S W>N W, p<0.05$. TC: total cholesterol; TG: triglycerides; LDL-C: low-density lipoprotein cholesterol; HDL-C: high-density lipoprotein cholesterol; NHDL-C: non high-density lipoprotein cholesterol.

involving children and adolescents (6-18 years old), found the frequency of $62 \%$ for dyslipidemias with increases in TC and/or TG and/or LDL-C and/or reductions in HDL-C. ${ }^{19}$ Another study in Londrina/PR with adolescents (11-16 years old) showed that
$61 \%$ of the subjects had dyslipidemia (elevated TC and/or TG and/or LDL-C and/or reduced HDL-C). ${ }^{20}$ Also, in 2007 a study of schoolchildren (10-14 years old) from Recife/PE described at least one type of dyslipidemia in $63.8 \%$ of the sample. ${ }^{21}$ 
Other works performed in North and South American countries showed lower frequencies. In the United States ${ }^{22}$ between 2011 and 2014, in individuals aged 6 to 19 years, the reported frequency of dyslipidemia was $21 \%$ (increased TC and/or NHDL-C and/or reduced HDL-C).

In Santiago, Chile ${ }^{23}$ (2009-2011) in 2,900 individuals aged 10 to 14 years, the frequency of dyslipidemia was $32 \%$ (elevated TC and/or TG and/or LDL-C and/or reduced HDL-C). The higher prevalence in the present study may have been caused in part by the lower cut-off values used by the national guideline $^{3}$ when compared to the international guidelines. ${ }^{19,20}$

In the analyses performed to evaluate the effect of sex, dyslipidemias were more frequent for all lipid parameters in females, and these results are consistent with national ${ }^{24}$ and international studies. ${ }^{25}$ In fact, variations in serum lipoprotein levels are inherent to these individuals in the developmental stages and, consequently, to variations in sex hormones. ${ }^{26}$

Some studies indicate that estrogens increase HDL-C in part due to their action in reducing hepatic lipase $(\mathrm{HL})$ activity and increasing ATP-binding cassette transporter $\mathrm{A} 1$ receptors (ABCA1). ${ }^{27}$ In addition, they decrease LDL-C ${ }^{27}$ levels by positively regulating LDL receptors, thus exerting a beneficial effect on the lipoprotein profile. ${ }^{28}$

On the other hand, androgens increase HL activity, leading to an inverse effect: ${ }^{27} \mathrm{HDL}-\mathrm{C}$ is reduced while LDL-C is increased. In contrast, Zhang et al. ${ }^{29}$ indicated that testosterone may be associated with changes in SR-B1 receptor and HL activity, facilitating the selective uptake of HDL and playing an antiatherogenic role. ${ }^{29}$

Comparisons by age groups revealed that infants presented higher levels of TG, NHDL-C and combination of LDL-C and TG as well as a high frequency of individual dyslipidemias; few studies report this data up to two years of age due to the difficulty of blood collection and metabolic instability in this phase of rapid growth before 24 months of life.$^{30}$ In addition, the high frequency of hypertriglyceridemia would occur through lactation and lack of food fasting. The current DBD defines the cut-off value of TG without fasting for the 0-9 years of age range as $\geq 85 \mathrm{mg} / \mathrm{dL}$. Evaluating this interference, we applied that cut-off value, and the results showed a lower frequency, 56\% instead of $67 \%$ ( $\geq 75 \mathrm{mg} / \mathrm{dL}$, with fasting).

In this context, it is also worth noting that according to the national guidelines, ${ }^{10}$ it is recommended to determine the lipid profile in children and adolescents when: i) grandparents, parents, siblings and first cousins present dyslipidemia, mainly severe or with manifestation of premature atherosclerosis; ii) in the presence of clinical signs of dyslipidemia; in the presence of other cardiovascular risk factors; iii) with involvement of other pathologies, and iv) in the use of contraceptives, immunosuppressants and other drugs that may lead to dyslipidemia. ${ }^{31}$ Therefore, it is expected that other factors, not collected here, would potentially justify these variations.

As for children, elevated TC and LDL-C were 40\% and 35\%, respectively. This increase in TC is close to that of a 2009 study with 217 individuals (84 obese), aged 2-9 years in Campina Grande/PB, ranging from $37 \%$ to $46 \% .^{32}$ Moreover, this result of TC in children is consistent with data from the National Health and Nutrition Examination Survey (NHANES) of individuals aged 4-19 years, where elevations of TC levels were observed in the 9-11 years age group, decreasing later along the pubertal development. ${ }^{33}$

Ramos et al. $(2011)^{32}$ reported that the increase in LDL-C ranged from $14 \%$ to $14.8 \%$ in children (non-obese and obese), a finding that is lower than that of our study (35\%). However, the cut-off value we used is lower than that of the referred population. In addition, similar results were observed in a study in Mexico with children from 2 to 10 years of age: $30 \%$ of subjects presented LDL-C $\geq 110 \mathrm{mg} / \mathrm{dL} .{ }^{34}$

As for adolescents, there was a high frequency of low HDL-C (41\%), a value close to the one reported in the ERICA study, which was $47 \%$ among 38,069 schoolchildren, ${ }^{8}$ results aligned with those of this study, even considering the different methodological approaches of the two studies.

Other national studies have shown important data. A study conducted in the Northeast, with individuals aged 6 to 18 years, showed a low HDL-C frequency of $41 \%,{ }^{19}$ and another one carried out in Natal, RN, with students aged between 10 and 19 showed that $50 \%$ of the sample had this type of dyslipidemia. ${ }^{35}$ Another study conducted in the metropolitan region of Guadalajara, Mexico with 132 individuals aged 5 to 15 years showed a lower prevalence (38.7\%), but not very different from our findings. ${ }^{36}$ The high frequency of reduced HDL-C in adolescents may be associated with young people's lifestyle, which involves inappropriate eating habits, overweight and physical inactivity. ${ }^{37}$

It is worth mentioning that in this study, 349 individuals presented serum phenotype with LDL-C $\geq 190 \mathrm{mg} / \mathrm{dL}$, that is in $0.56 \%(1: 200)$ the results were suggestive for $\mathrm{FH}^{10}$

In relation to the regions of Campinas, the frequency of dyslipidemias was higher in the south and southwest than in the other regions. According to unpublished reports from the City Hall of Campinas, these regions have the highest number of records $(25.7 \% \text { and } 27.6 \% \text {, respectively })^{38}$ in the Cadastro Único, a platform of the Federal Government that characterizes low-income families. In fact, according to Johansen et al., ${ }^{12}$ they make up the so-called "poverty mountain range", where there is a socioeconomic homogeneity not observed in the other regions. ${ }^{39}$ Additionally, they are the ones that have a greater number of SUS users, accounting for $50 \%$ of the test results in this study.

Socioeconomic asymmetry can compromise the lifestyle of populations with direct repercussions on morbidity and mortality indicators. According to the WHO, currently three-quarters of deaths from cardiovascular disease are occurring in low and middle-income regions. ${ }^{1}$

The ERICA study showed significant increases in dyslipidemias in the north and northeast regions of the country (regions reportedly with the highest poverty indices in Brazil); ${ }^{40}$ also, ERICA suggests that regional differences in dyslipidemias occur through the process of epidemiological transition, that is, regions may be at different stages. ${ }^{8}$

This study evaluated the second most populous city in the state of São Paulo, located in the southeastern region of Brazil, where urban sprawl occurred without adequate planning and culminated in the expansion of occupation areas with the consequence for the population of inappropriate access to urban services. ${ }^{12}$ 


\section{Limitations of the study}

One of the limitations concerns the fact that the evaluated database is of secondary origin, with possible inaccuracies in the insertion of demographic data throughout all the processes. We are aware of the continued use of the quality control standards of the Brazilian Society of Clinical Pathology by the Municipal Laboratory of Campinas, which supplies the laboratory data.

In addition, since it was a cross-sectional study, it was not possible to evaluate the incidence of cases of dyslipidemia.

\section{Conclusion}

This study shows the high frequency of atherogenic dyslipidemias in adolescents, children and infants attended in Campinas, with a greater distribution in the less favored socioeconomic regions, indicating the need for a regionalized focus during the development of public health programs for the prevention of early and adulthood CVD, including proper handling and treatment of dyslipidemias.

\section{Acknowledgements}

To the Secretaria de Saúde de Campinas for the availability of the database for the study, to the Conselho Nacional de Desenvolvimento Científico e Tecnológico (CNPq); protocol 481863/2011-7, and to the Fundação de Amparo à Pesquisa do Estado de São Paulo (FAPESP); protocol 2006/60585-9 for the research grants. The authors also are grateful to the Espaço da Escrita - Pró-Reitoria de Pesquisa - UNICAMP - for the translation of the manuscript to English. This study was part of the masters'degree of Erica I. L. Gomes.

\section{Author contributions}

Conception and design of the research, Acquisition of data and Obtaining financing: Faria EC; Analysis and interpretation of the data: Gomes EIL, Faria EC; Statistical analysis: Gomes EIL; Writing of the manuscript and Critical revision of the manuscript for intellectual content: Gomes EIL, Zago VHS, Faria EC.

\section{Potential Conflict of Interest}

No potential conflict of interest relevant to this article was reported.

\section{Sources of Funding}

This study was funded by FAPESP process no 2006/60585-9.

\section{Study Association}

This article is part of the thesis of master submitted by Érica Ivana Lázaro Gomes, from Universidade Estadual de Campinas.

\section{Ethics approval and consent to participate}

This study was approved by the Ethics Committee of the Unicamp under the protocol number CAAE: 86627418.3.0000.5404 № do parecer: 2.662.289. All the procedures in this study were in accordance with the 1975 Helsinki Declaration, updated in 2013.

\section{References}

1. World Health Organization (WHO). Cardiovascular diseases (CVDs). 2017; Available from: http://www.who.int/en/news-room/fact-sheets/detail/ cardiovascular-diseases-(cvds).

2. Sociedade Brasileira de Cardiologia . Cardiômetro: Mortes por doenças cardiovasculares no Brasil. 2015; Available from: http://www.cardiometro. com.br/.

3. Faludi AA, Izar MC, Saraiva JF, Chacra AP, Bianco HT, Afiune Neto A, et al. Atualização da Diretriz Brasileira de Dislipidemias e Prevenção da Aterosclerose - 2017. Arq Bras Cardiol. 2017;109(2 Suppl 1):1-76.

4. Roth GA, Huffman MD, Moran AE, Feigin V, Mensah GA, Naghavi M, et al. Global and regional patterns in cardiovascular mortality from 1990 to 2013. Circulation. 2015;132(17):1667-78.

5. Brasil.Leis, Decretos. Lei n. 8.069, de 13 de julho de 1990, e legislação correlata. Dispõe sobre o Estatuto da Criança e do Adolescente. DOU de 16/07/1990 - ECA; Brasilia,2012.

6. Napoli C, D'Armiento FP, Mancini FP, Postiglione A, Witztum JL, Palumbo $\mathrm{G}$, et al. Fatty streak formation occurs in human fetal aortas and is greatly enhanced by maternal hypercholesterolemia. Intimal accumulation of low density lipoprotein and its oxidation precede monocyte recruitment into early atherosclerotic lesions. J Clin Invest. 1997;100(11):2680-90.

7. Zachariah JP, Johnson PK. Pediatric Lipid Management An Earlier Approach. Endocrinol Metab Clin North Am. 2014·43(4):981-92.
8. Faria-Neto J, Bento V, Baena C, Olandoski M, Goncalves L, Abreu G, et al ERICA: prevalence of dyslipidemia in Brazilian adolescents. Rev Saude Publica. 2016;50(Suppl 1):10s.

9. Faria EC, Dalpino FB, Takata R. Lípides e lipoproteínas séricos em crianças e adolescentes ambulatoriais de um hospital universitário público. Rev Pau Pediatr. 2008;26(1):54-8.

10. Xavier HT, Izar MC, Faria Neto JR, Assad MH, Rocha VZ, Sposito AC, et al $\checkmark$ Brazilian Guidelines on Dyslipidemias and Prevention of Atherosclerosis. Arq Bras Cardiol. 2013;101(4 Suppl 1):1-20.

11. Kwiterovich PO. Recognition and management of dyslipidemia in children and adolescents. J Clin Endocrinol Metab. 2008;93(11):4200-9.

12. Johansen IC, Carmo RL, Alves LC. Desigualdade social intraurbana: implicações sobre a epidemia de dengue em Campinas, SP, em 2014. Cad Metrop. 2016;18(36):421-40

13. São Paulo. Estado. Secretaria de Saúde de Campinas. Estrutura - SUS Campinas. Campinas: Prefeitura Municipal de Campinas; 2017 [Citado 2018 abr 16] Disponível em: http://www.saude.campinas.sp.gov.br/saude/.

14. Berenson GS, Srinivasan SR, Bao W, Newman WP, Tracy RE, Wattigney WA Association between multiple cardiovascular risk factors and atherosclerosis in children and young adults. The Bogalusa Heart Study. N Engl J Med. 1998;338(23):1650-6. 
15. Dwyer T, Sun C, Magnussen CG, Raitakari OT, Schork NJ, Venn A, et al. Cohort Profile: the international childhood cardiovascular cohort (i3C) consortium. Int J Epidemiol. 2013;42(1):86-96.

16. Magnussen CG, Raitakari OT, Thomson R, Juonala M, Patel DA, Viikari JS, et al. Utility of currently recommended pediatric dyslipidemia classifications in predicting dyslipidemia in adulthood: evidence from the Childhood Determinants of Adult Health (CDAH) study, Cardiovascular Risk in Young Finns Study, and Bogalusa Heart Study. Circulation. 2008;117(1):32-42.

17. Magnussen CG, Venn A, Thomson R, Juonala M, Srinivasan SR, Viikari JSA, et al. The Association of Pediatric Low- and High-Density Lipoprotein Cholesterol Dyslipidemia Classifications and Change in Dyslipidemia Status With Carotid Intima-Media Thickness in Adulthood Evidence From the Cardiovascular Risk in Young Finns Study, the Bogalusa Heart Study, and the CDAH (Childhood Determinants of Adult Health) Study. J Am Coll Cardiol. 2009;53(10):860-9.

18. Juonala M, Magnussen CG, Venn A, Dwyer T, Burns TL, Davis PH, et al. Influence of Age on Associations Between Childhood Risk Factors and Carotid Intima-Media Thickness in Adulthood The Cardiovascular Risk in Young Finns Study, the Childhood Determinants of Adult Health Study, the Bogalusa Heart Study, and the Muscatine Study for the International Childhood Cardiovascular Cohort (i3C) Consortium. Circulation. 2010;122(24):2514-20.

19. Quadros TM, Gordia AP, Silva RC, Silva LR. Predictive capacity of anthropometric indicators for dyslipidemia screening in children and adolescents. J Pediatr. 2015;91(5):455-63.

20. Tomeleri CM, Ronque ER, Silva DR, Cardoso Júnior CG, Fernandes RA, Teixeira DC, et al. Prevalence of dyslipidemia in adolescents: comparison between definitions. Rev Port Cardiol. 2015;34(2):103-9.

21. Pereira PB, Arruda IK, Cavalcanti AM, Diniz AA. Lipid profile of schoolchildren from Recife, PE. Arq Bras Cardiol. 2010;95(5):606-13.

22. Nguyen D, Kit B, Carroll M. Abnormal Cholesterol Among Children and Adolescents in the United States, 2011-2014. NCHS Data Brief. 2015 Dec;(228):1-8.

23. Barja Yáñez S, Arnaiz Gómez P, Villarroel Del Pino L, Domínguez de Landa A, Castillo Valenzuela O, Farías Jofré M, et al. Dyslipidemias in school-age chilean children: prevalence and associated factors. Nutr Hosp. 2015;31(5):2079-87.

24. Franca E, Alves JG. Dyslipidemia among adolescents and children from Pernambuco. Arq Bras Cardiol. 2006;87(6):722-7.

25. Kit BK, Kuklina E, Carroll MD, Ostchega Y, Freedman DS, Ogden CL. Prevalence of and trends in dyslipidemia and blood pressure among US children and adolescents, 1999-2012. JAMA Pediatr. 2015;169(3):272-9.

26. Sociedade Brasileira de Cardiologia. I Diretriz de Prevenção da Aterosclerose na Infância e na Adolescência. Arq Bras Cardiol. 2005;85(6):3-36.
27. Styne DM, Grumbach MM. Physiology and disorders of puberty. Williams Textbook of Endocrinology. 13 th ed. Philadelphia, PA: Elsevier; 2016.

28. Vashishta S, Gahlot S, Goyal R. Effect of Menstrual Cycle Phases on Plasma Lipid and Lipoprotein Levels in Regularly Menstruating Women. J Clin Diagn Res. 2017;11(5):CC05-7

29. Zhang N, Zhang HQ, Zhang X, Zhang BC, Wang FR, Wang CG, et al. The relationship between endogenous testosterone and lipid profile in middleaged and elderly Chinese men. Eur J Endocrinol. 2014;170(4):487-94 .

30. Rabelo LM. Atherosclerotic risk factors in adolescence. J Pediatr. 2001;77(Suppl 2):S153-64.

31. Bibbins-Domingo K, Grossman DC, Curry SJ, Davidson KW, Epling JW, Garcia FA, et al. Screening for Lipid Disorders in Children and Adolescents: US Preventive Services Task Force Recommendation Statement. JAMA. 2016;316(6):625-33.

32. Ramos AT, Carvalho DF, Gonzaga NC, Cardoso AD, Noronha JA, Cardoso MA. Lipid profile in overweight children and adolescents. Journal of Human Growth and Development. 2011;21(3):780-8.

33. Hickman T, Briefel R, Carroll M, Rifkind B, Cleeman J, Maurer K, et al. Distributions and trends of serum lipid levels among United States children and adolescents ages 4-19 years: Data from the third National Health and Nutrition Examination Survey. Prev Med. 1998;27(6):879-90.

34. Bibiloni M, Salas R, Novelo H, Villarreal J, Sureda A, Tur J. Serum Lipid Levels and Dyslipidaemia Prevalence among 2-10 Year-Old Northern Mexican Children. Plos One. 2015.2015;10(3): e0119877.

35. Vieira Cunha Lima SC, Oliveira Lyra C, Galvão Bacurau Pinheiro L, Medeiros de Azevedo PR, Arrais RF, Campos Pedrosa LF. Association between dyslipidemia and anthropometric indicators in adolescents. Nutr Hosp. 2011;26(2):304-10.

36. Romero-Velarde E, Campollo-Rivas O, Celis de la Rosa A, Vásquez-Garibay EM, Castro-Hernández JF, Cruz-Osorio RM. Risk factors for dislypidemia in obese children and adolescents. Salud Publica Mex. 2007;49(2):103-8.

37. Martinez-Gomez D, Rey-Lopez J, Chillon P, Gomez-Martinez S, Vicente-Rodriguez G, Martin-Matillas M, et al. Excessive TV viewing and cardiovascular disease risk factors in adolescents. The AVENA cross-sectional study. BMC Public Health. 2010 May;10:274.

38. São Paulo. Estado. Prefeitura de Campinas. Perfil das pessoas e famílias no cadastro unico em Campinas. In: Socioassistencial V, editor. Campinas;2015.

39. Cunha JM, Jakob AA, Jiménez MA, Trad IL. Expansão metropolitana, mobilidade espacial e segregação nos anos 90: o caso da RM de Campinas.In: 11 Encontro nacional da associação nacional de pós graduação em planejamento urbano e regional. Salvador/BA. Anais; 2005. p. 1-21.

40. Instituto Brasileiro de Geografia e Estatística (IBGE). Síntese de indicadores sociais: uma análise das condições de vida da população brasileira. Rio de Janeiro; 2017. 
